\title{
On the Economies of Scale and Budget Allocations in Information Technology Services Provision
}

\author{
Sunil Mithas \\ University of Maryland \\ smithas@rhsmith.umd.edu
}

\author{
Kunsoo Han \\ McGill University \\ kunsoo.han@mcgill.ca
}

\author{
M.S. Krishnan \\ University of Michigan \\ mskrish@umich.edu
}

\begin{abstract}
This study reexamines some fundamental questions in the network era of computing using the data after 1995 when firms have made significant investments in newer types of IT systems. Our findings suggest that firms realize some economies of scale in IT services as they grow in size. We also find that the personnel-hardware ratio is not independent of IT budget. Finally, we find that personnelhardware ratio was declining during 1999-2003 period in response to changes in factor prices of hardware and personnel. We discuss implications of these results for academic research and for managerial practice.
\end{abstract}

\section{Introduction}

Worldwide information technology (IT) spending increased from \$1.01 trillion dollars in 1996 to \$3.5 trillion dollars in 2011. During this period, firms invested significantly in enterprise resource planning, customer relationship management, knowledge management, and other systems that were relatively rare prior to 1995. Given their reach and range, some argue that new information technology systems have far greater transformational potential compared to their predecessor systems. Some of this is reflected in likely changes in relative allocations from Advertising and R\&D to IT at the firm level [1] and substitutions within various IT inputs such as hardware and labor.

Previous empirical analysis of firm-level IT investments has focused on three research questions: (1) Do IT investments exhibit economies of scale [2], i.e., do firms reduce their IT investments as they grow in size to the extent that a larger firm size allows for economies of scale in providing IT services to a firm? ${ }^{1}$ (2) What is the nature of the production function for IT services, in particular, is the ratio of personnel to hardware independent of IT budget? [2, 3]? and, (3) Has the elasticity of substitution between labor and hardware remained fixed over the years [3]? Based on econometric analysis of time-series cross-sectional data on firms and information systems (IS) units with sample sizes ranging from 16 to 42 over the 1989-1994 period, Gurbaxani and colleagues [2,3] found that there were no measurable economies of scale in the provision of information services, the personnel-hardware ratio in IT investments was independent of scale of the IS organization, and this ratio did not change in response to change in relative prices of personnel and hardware in their data.

The nature of IT services and their production function has undergone significant changes since 1994 in at least three ways [4]. First, firms make much greater use of software package applications such as enterprise resource planning systems that require significant upfront investments in design and development by a vendor but require relatively less effort and customization in rolling out the package at a customer's end compared to a fully custom-made software development project as was common before 1994. Second, use of Internet era open standards such as TCP/IP and XML have facilitated a relatively seamless integration of disparate systems reducing the complexity of overall IT infrastructure. Finally, firms are making significant use of IT outsourcing and offshoring services to leverage enhanced software development quality and reduced labor costs

\footnotetext{
${ }^{1}$ Note that economy of scale and return to scale are two related but different concepts. Economy of scale is about the cost advantages due to increased output, whereas return to scale is about the production function or the increase in output relative to the increase in input. In our context, larger firm size may enable economies of scale in delivering IT services, and as a result firms may also be able to obtain higher output (say revenues, profits or intangibles such as customer satisfaction and innovation) using IT.
} 
at vendor firms often located in emerging economies with the highest levels of CMM certification [5, 6]. Thus, beyond the continuation of Moore's law and associated decline in hardware prices, application of newer types of IT systems as well as declining labor costs due to outsourcing in the network era suggest that findings of prior research using IT budget data prior to 1995 may no longer hold. Therefore, we reexamine the research questions related to IT investments explored in the prior work by using firmlevel data for the more recent period 1999-2003, chosen specifically to capture the application of newer information technologies and extensive adoption of outsourcing and offshoring.

Besides the difference in time period, our analysis differs from prior studies in two significant ways. First, in contrast to previous studies that used modest sample sizes of 16-42, potentially dampening the power of statistical tests, our study uses much larger sample sizes (137-409). Second, we relax the assumption made in previous research that all firms face the same prices for hardware and labor by employing a random effects model to control for unobserved firm-level heterogeneity - including the possibility that firms face different prices.

Our findings based on IT budget data for U.S. firms for the 1999-2003 period differ significantly from those of prior studies examining earlier time periods (1989-1994). First, we find that firms realize economies of scale in IT services as they grow in size. Second, we find that the personnel-hardware ratio in IT investments depends on the scale of the IS organization. Finally, we find that the personnelhardware ratio was declining over this period and we quantify the shifts in allocation of IT budget from IT labor to IT hardware.

\section{Background and Theory}

The primary source of economic growth in advanced economies is shifting from manufacturing to services. Knowledge about how to enhance the efficiency and effectiveness of service processes is thus increasingly valuable to managers and public policy makers, especially given the complexities of global business and Internet technologies. The shift towards services and a greater use of networked technologies are transforming services by enabling the disaggregation and dispersion of the service production process $[5,7]$, raising complexity while expanding the innovation horizon and enabling new sources of growth.

Given the rapid pace of technological change in many services, including information systems, it is important to incorporate the time dimension in any analysis because the nature of information systems has been changing across computing eras. Thus, our approach is to adapt methods from production economics to analyze key inputs to the IS services production process - hardware and labor - against the backdrop of eras of computing.

\subsection{IT Services Production}

IT services include the design, development, and maintenance of information systems and encompass a wide range of organizational resources, including people, processes, and technologies. For example, hospital administrators may collaborate with information systems developers to develop a new RFID system for tracking patients in a hospital. Even this relatively straightforward scenario, however, is deceptively complex, involving new work processes, shifting job functions, technology evolution, new information management requirements, and privacy concerns, to name a few. Case studies provide rich details into how managers have developed these interdependent aspects of IS service production into an effective service production system [8]. Our approach is complementary, and by modeling information services at a higher level of abstraction, we identify systematic resource allocation patterns across large groups of firms, adding to our knowledge of the IS service production process.

The allocation of IS budgets across hardware, software, labor, and consulting services components is shaped by the era of computing. Qualitatively, entirely new application models, networked information systems, and modes of IT service production have appeared. For example, in recent years, sweeping technological progress related to the Internet has enabled firms to increase their use of outsourced IT services. Quantitatively, exponential improvements in price-performance trends in hardware captured by Moore's Law and steady increases in web-based sales are two measures evidencing Internet transformation. Clearly, analysis of IT services production - inherently dynamic requires incorporation of the era of computing. We thus develop our conceptual framework and associated hypotheses against the backdrop of eras of computing.

\subsection{IT Services Production: Mainframe, mini, and PC Eras}

From a computing perspective, researchers often characterize the period before 1995 in three 
overlapping but distinct eras: mainframe, minis, and PC.

Mainframe Era. One of the earliest forms of IT service production in business involved the use of mainframe computers for processing data such as accounting calculations [9, 10]. Inputs to this 1960sera IT service production process included technical experts, hardware, and software; outputs included solved computations such as payroll. Given rapid declines in hardware costs, debate arose over the allocation of IS budgets to hardware and software. Although neoclassical production economics suggested that the budget allocated to hardware versus other inputs would increase over time, empirical evidence indicated the contrary: roughly constant budget shares over time [11].

Mini and PC Era. The introduction of lowerpriced minicomputers in the 1970s enabled computing to migrate away from centralized corporate management to organizational subunits such as departments. As business managers become physically proximate to the source of IT service production, they began to team with IT experts to develop applications tailored to specific business problems. This trend of smaller-sized computing systems becoming more widely dispersed throughout organizations continued in the 1980s and early 1990s with the introduction of the desktop personal computer and local area networks (LAN).

Dispersion of Organizational Computing Reinvigorates Budgets Debate. Given increased ubiquity of computing, continued price-performance improvement, and significant costs savings and strategic advantages via properly managed information systems, the salience of IS in organizations catapulted during the PC computing era that began in the $1980 \mathrm{~s}$. This reinvigorated the mainframe-era budget allocation debate, with researchers asking more specific questions about the behavior of inputs to the IT services production process $[12,13]$. A key advancement in the literature was the application of a theoretically rigorous framework - microeconomic production theory - to enable a more precise empirical analysis of these questions.

The IT services literature that emerged focused on a set of empirical analyses applying a rigorous theory to improve understanding of the forces underlying the production of IT services, and thereby improve the practice of IS management. Research utilizing data from earlier computing eras at the economy level of analysis found that the production of IT services can be characterized by a Cobb-Douglas (CD) production function [12] which implies constant returns to scale, that is, if inputs such as hardware and software increase by a factor of two, then output also increases by a factor of two - not too promising for managers living in a world of increasing returns to scale in large industrial firms.

Because the form of IT services production at the economy level may not be reflected at the firm level, researchers also used firm-level data to examine similar questions. Production function analysis of cross-sectional and time-series data on IT budgets in the PC/LAN era found that IT services production was consistent with the CD production function labor-hardware ratio that is independent of scale and fixed over time [2, 3]. Moreover, analysis of alternative data within this same computing era indicated that IT is a net substitute for regular capital and labor, suggesting that the overall IT services budget might increase over time to leverage its priceperformance profile [14]. Taken together, empirical evidence from earlier computing eras appeared consistent with the $\mathrm{CD}$ production function and suggested that managers were behaving rationally, resulting in constant budget shares over time.

However, empirical findings examining IT service production from earlier eras reflect underlying processes for producing IT services of those eras. If these underlying processes - at least with respect to microeconomic production function modeling - have changed substantially, the model for IT service production may have also changed, with implications for both management and research.

\subsection{IT Services Production: Network Era}

The current computing era since about 1995 is substantially different from earlier eras due to the prevalence of the Internet and business applications that emerged in the late 1990s. The Internet emerged as the standard networking infrastructure throughout the world. Standards for developing software applications atop the Internet and Web infrastructures alter how software is produced, with open source and what have come to be characterized as Web 2.0 applications being two examples. Other pertinent phenomena include the disaggregation of IT services production enabled by cheap and instantaneous worldwide communication as well as new application categories.

Given fundamental differences between prior eras of computing and the current era, we might expect that IT services production would be altered, including key characteristics of economies of scale, substitutability of inputs, etc. However, few quantitative empirical studies examine IT services production from a microeconomic perspective to explore questions related to budget allocation using 
data from the network computing era. We build upon and extend prior research on IT services production by reexamining the nature of IT services across rapidly changing computing environments.

\subsection{Hypotheses}

In recent years, IT has become a global operation, with outsourced or partially outsourced services mixed with in-house IT services. Such global collaborative IT services production pervades multinational firms, and represents a qualitative change in how IT services are specified and delivered. A greater degree of collaboration is now required across national and cultural borders, raising the complexity of project specification, execution, and performance measurement. From a technical perspective, enterprise architecture maturity may play a large role in shaping the optimal type of outsourcing arrangement.

Knowledge flows and agglomeration effects also alter the fundamental dynamics of the IT service production process. A major outsourcing firm may have relationships with several competing industry firms, meaning that, for example, software coding best practices may be diffused rapidly via this bestpractice offshore provider [15]. Moreover, agglomeration effects of IT service providers reinforce best practices and enable them to be diffused quickly throughout client organizations [16]. Taken together, knowledge spillovers and agglomeration effects drive an acceleration in knowledge production and distribution among client firms.

In addition to knowledge spillovers engendered by global IT sourcing, standardization on web-based standards enables systematization of certain elements of IT services production. For example, standardized global communication has enabled standardization of user help lines, which are often aggregated and serviced by outsourced providers. In sum, the emergence of a global IT services industry, which diffuses best practices, together with standardization on web-based computing platforms, would imply a shift in economies of scale.

As discussed earlier, prior research has demonstrated no economies of scale in IT services for earlier computing eras. However, the current era of globalization and web standards implies a shift toward systematization of IT services analogous to what happened in manufacturing in the Fordist era [17]. This implies that as firms increase in size, their IT budget will not need to grow proportionally to maintain service production levels. In other words, we argue that economies of scale arise due to two mechanisms: (1) knowledge spillovers created by emergence of global IT service providers, and (2) virtualization of servers, and standardization of webbased computing platforms compared to previous eras when firms used dedicated and underutilized hardware, and most of the IT development was customized and client specific. Thus, we hypothesize that:

H1: There are positive economies of scale in IT services production in the Internet computing era.

Prior research using data from earlier computing eras found that the production of IS services exhibits homotheticity, i.e., the optimal ratio of inputs is independent of scale for a given set of prices. In the case of non-homotheticity, the optimal ratio of inputs depends on scale.

However, in the network era characterized by complex global outsourcing arrangements, homotheticity may not hold. First, the range of production modalities has vastly expanded, including in-sourcing, outsourcing, and partial outsourcing. This means that there are multiple ways of producing IS services, each of which may have different dynamic scale characteristics. Second, given the possibility of economies of scale as proposed in Hypothesis 1, the mix of inputs may vary according to the extent of scale, as found in other services industries, such as hospitals. As a result, a firm may use a different optimal ratio depending on its size. Thus, we hypothesize that:

H2: Homotheticity of IT services production does not hold in the Internet computing era. In particular, the ratio of labor to hardware varies with scale.

In addition to economies of scale and optimal input ratios, the substitutability of inputs is a key characteristic of IS service production. From a practical perspective, substitutability characterizes the extent to which one input (say hardware) may be substituted for another (say labor) while maintaining constant output (say revenues, profits, or intangibles such as customer satisfaction and innovation). In earlier computing eras, budget shares were found to be constant with time, i.e., dollars spent on hardware relative to those spent on labor did not change from year to year. This result was consistent with a CobbDouglas (CD) production function (CD is a special case of the constant elasticity of substitution (CES) production function, with the constraint of unitary elasity of subtitution). 
Several phenomena underlying CD production have changed in the Internet era. First, a plethora of new inputs, such as offshoring and outsourcing, have been added to the service production input set. This has raised the complexity of managerial decision making concerning budget allocation, as evidenced by myriad articles in the professional press about when and how to use outsourcing for optimal results. Second, the prices of inputs change at different rates, making it more difficult for managers to substitute optimally based on changes in prices over a longterm planning horizon. Examples include the shift from fully custom-made software development to use of package implementations and greater use of outsourcing/offshoring with major implications for how managers understand the pricing of software. Given changes in the underlying dynamics of the $\mathrm{CD}$ production function, we do not expect the CD assumptions of fixed and unitary elasticity of substitution to obtain in the network era. This implies changing budget shares with time, rather than fixed shares. We thus hypothesize that:

H3: IS service production is not characterized by Cobb-Douglas production in the Internet computing era. In other words, the ratio of personnel to hardware changes with time in response to changes in relative prices of personnel and hardware.

\section{Research Methodology}

\subsection{Data Sources}

Our analysis comprises the estimation of empirical models using secondary data from two sources. First, we obtained IT-related data from InformationWeek, a leading and widely circulated IT publication in the U.S. InformationWeek collected this data annually by surveying the top IT managers of large U.S. firms during the period 1999-2003. Quite a few academic studies have used data from InformationWeek surveys [18, 19]. Second, we matched the InformationWeek data with revenue and industry data from Compustat for publicly traded firms.

\subsection{Variable Definitions}

Hardware $(H)$ represents tangible IT equipment, as distinguished from software, labor, and other dimensions of information technology. We operationalize $H$ in our study by the sum total of all hardware technology purchases, including hardware, networking gear, and peripherals.

The $P$ variable represents IT labor expenses and is operationalized as total personnel expenses associated with salaries and benefits of IT staff.

The $B$ variable denotes total IS expenses, operationalized as the sum of all expenses incurred by IS, including capital and operating expenses for infrastructure (telecom, networking, hardware, applications maintenance, applications development, and packaged applications); Internet-based costs; salaries and recruitment; IT services and outsourcing; and training. ${ }^{2}$

The $R$ variable represents revenues or the scale of the firm, which is operationalized as net sales (Compustat), consistent with prior literature [2].

We deflated all figures to 1990 constant dollar values using appropriate GDP deflators. Table 1 shows summary statistics.

Table 1. Summary Statistics $(\mathrm{N}=1014)$

\begin{tabular}{|lrr|}
\hline & Mean & \multicolumn{1}{c|}{ S.D. } \\
\hline Revenue $(R)^{1}$ & 7545.78 & 14814.14 \\
\hline${\text { IT Budget }(B)^{1}}^{1}$ & 228.78 & 455.83 \\
\hline${\text { IT Hardware Budget }(H)^{1}}^{1}$ & 43.99 & 98.42 \\
\hline IT Personnel Budget $(P)^{1}$ & 63.00 & 126.12 \\
\hline $\begin{array}{l}\text { Hardware as a percentage of } \\
\text { IT Budget }\end{array}$ & 18.28 & 10.43 \\
\hline $\begin{array}{l}\text { Personnel as a percentage of } \\
\text { IT Budget }\end{array}$ & 31.55 & 13.51 \\
\hline Personnel to Hardware Ratio & 2.62 & 3.13 \\
\hline $\begin{array}{l}\text { Note: }{ }^{1} \text { All figures are in 1990 million constant US dollars } \\
\text { using GDP deflators. }\end{array}$
\end{tabular}

\subsection{Empirical Models and Econometric Considerations}

First, we test whether IT budgets show economies of scale. Following Gurbaxani et al. [2], we specify the following model to test for the existence of economies of scale (as far as possible, we use the same notation used by Gurbaxani et al. [2, 3] to permit an easy comparison of our approach and findings with their studies):

$$
\ln B=C+D \cdot \ln R+\varepsilon
$$

where $B$ is total IT budget; $R$ is firm revenue as a proxy for scale of firm; $C$ and $D$ are regression

\footnotetext{
${ }^{2}$ We did not exclude software from IT budget, but did not conduct analyses using software as a dependent variable in Tables 4 and 5 because we wanted to compare our findings with that of Gurbaxani et al. [2].
} 
parameters and $\varepsilon$ is the usual disturbance term. In this specification, rejecting the null of $D=1$ implies rejecting the existence of economies of scale.

Second, we use a linear model to test for homotheticity. Similar to Gurbaxani et al. [2, 3], we use IT budget as an indicator of scale of IT operations. We first test the homotheticity assumption using the following model:

$$
P / H=C+D \cdot B+\varepsilon
$$

where $P$ denotes personnel, $H$ denotes hardware, $B$ denotes total IT budget and $\varepsilon$ is the usual disturbance term. In this model, rejection of $D=0$ signifies rejection of the homotheticity assumption.

Note that Equation 2 does not distinguish between changes in hardware versus personnel - firms may shift the personnel-to-hardware ratio by changing the personnel and hardware components in many different ways. An alternative way to test the homotheticity assumption is to regresses hardware and personnel budgets on total IT budget separately as in the following specifications.

$$
\begin{aligned}
& \ln H=C_{h}+D_{h} \ln B+\varepsilon_{h} \\
& \ln P=C_{p}+D_{p} \ln B+\varepsilon_{p}
\end{aligned}
$$

For equations $3 \mathrm{~A}$ and $3 \mathrm{~B}$, we reject the null hypothesis if $D_{h} \neq D_{p}$.

Third, to test whether IT services follow the CD or CES function, we note that $\mathrm{CD}$ has fixed and unitary elasticity of substitution while CES only has fixed but not necessarily unitary elasticity of substitution. In other words, CD is a special case of CES when substitution elasticity equals one. We use our longitudinal data spanning several years to distinguish between CD and CES specifications with the logic that decreasing hardware prices as predicted by Moore's law will lead to a change in budget shares of hardware relative to labor only if the CES obtains. Gurbaxani et al. [2, 3] use a similar method to test this hypothesis with their data. We use the following specifications to test this hypothesis.

$$
\begin{aligned}
& \ln H=C_{h 0}+C_{h l} M_{l}+\ldots+C_{h T} M_{T}+D_{h 0} \ln B+D_{h l} \\
& M_{l} \cdot \ln B+\ldots+D_{h T} M_{T} \cdot \ln B+\varepsilon_{h} \\
& \ln P=C_{p 0}+C_{p l} M_{l}+\ldots+C_{p T} M_{T}+D_{p 0} \ln B+D_{p l} \\
& M_{l} \cdot \ln B+\ldots+D_{p T} M_{T} \cdot \ln B+\varepsilon_{P}
\end{aligned}
$$

In these models, $M_{t}=1$ for year $t$, else 0 . The null hypothesis for retaining the $\mathrm{CD}$ production function holds if $D_{h o}=D_{p 0} ; D_{h t}=D_{p t} ; C_{h t}=C_{p t} ; t=1,2, \ldots, T$.

Leveraging the panel nature of our dataset, we estimate Equation 1 and 2 using fixed and random effects models. Random effects models not only allow correlations among residuals of firms across time periods, but also account for unobservable firmspecific effects. We tested for the significance of random effects using the Breusch and Pagan Lagrange multiplier (LM) test. This test statistic exceeded the critical value of chi-square with one degree of freedom, rejecting the null hypothesis and favoring the random effects model. Since the random effects specification provides consistent estimates only if firm-specific effects are uncorrelated with other explanatory variables, we used the Hausman specification test to evaluate the validity of this independence assumption. Our failure to reject the null under this test provided further justification for the appropriateness of the random effects models. We also estimated the alternative fixed effects specification that accounts for unobserved heterogeneity by computing within-firm estimates of coefficients. We obtained essentially similar coefficients in our fixed effects models, providing greater confidence in our random effects model results.

Note that our random effects models allow each firm to have its own intercept enabling us to control for any potential industry effects with better granularity, therefore we do not control for industry dummies. Also, Gurbaxani et al. [2] did not find any industry effects (see their Table 8). We also did not include any interaction terms because we wanted to be able to compare our findings with that of Gurbaxani et al. who also did not use such interactions.

Finally, as in previous studies [2, 3], we use seemingly unrelated regression estimation (SURE) for estimating equations 3 and $4 .^{3}$

\section{Results}

We find support for hypothesis 1 which predicted that IT budgets in the networking era would show economies of scale. Column 1 of Table 2 shows that the elasticity of IT budget with respect to firm revenues is less than one (Wald test, $z=2.63$, $p=0.009$ ).

\footnotetext{
${ }^{3}$ Note that the gains in efficiency do not apply if equations in the SURE model use same regressors, and though OLS would yield the same results as SURE, the use of SURE in such situations makes it possible to impose restrictions on parameters estimates, such as equality of parameters across equations, a property that we make use of in testing $\mathrm{H} 3$.
} 
Table 2: Parameter Estimates of Random Effects Model for Economies of Scale $(\mathrm{n}=1,014)$

\begin{tabular}{|ll|}
\hline & $(1)$ \\
\hline & $\ln$ (IT Budget) \\
\hline $\ln$ (Revenue) & $\begin{array}{l}0.926^{* * *} \\
(0.000)\end{array}$ \\
\hline R-squared & $69 \%$ \\
\hline Wald Chi-squared & $1,085.58^{* * *}$ \\
\hline Number of Firms & 378 \\
\hline
\end{tabular}

Notes: Model has an intercept and controls for year dummy variables. $p$ values in parentheses $*$ significant at $10 \%$; ** significant at $5 \%$; *** significant at $1 \%$

Our results in Table 3 provide partial support for hypothesis 2 which stated that the homotheticity assumption (homotheticity assumption implies that the ratio of personnel to hardware is independent of IT budgets) would not hold in the 1999-2003 period. Table 3 uses the random effects specification used to test for homotheticity using equation 2 .

Table 3: Random Effect Models for PersonnelHardware Ratio $(\mathrm{n}=1,014)$

\begin{tabular}{|l|l|}
\hline & $(1)$ \\
\hline & Personnel-Hardware \\
& Ratio \\
\hline IT Budget (B) & $-0.503^{* *}$ \\
& $(0.021)$ \\
\hline R-squared & $4.1 \%$ \\
\hline Wald Chi-squared & $43.64 * * *$ \\
\hline Number of Firms & 378 \\
\hline
\end{tabular}

Notes: Model has an intercept and controls for year dummy variables. $p$ values in parentheses; * significant at $10 \%$; ** significant at $5 \% ; * * *$ significant at $1 \%$

The coefficient of IT budget in Table 3 is negative and statistically significant for the personnel-hardware ratio. Note that this model, as in Gurbaxani et al. study has very low explanatory power. However, in contrast with their study where the model as a whole was not significant, the global $\mathrm{F}$ statistic in all models is statistically significant. Thus, we reject the homotheticity assumption for changes in personnel budget with respect to hardware budget. Although our result provides evidence that the homotheticity assumption does not hold in the 1999-2003 period, it does not provide information on how firms have allocated IT budget among labor and hardware differentially. Table 4 examines that question.
Table 4: Parameter estimates of SURE Models to Test for Relative Allocations of IT Budget to Personnel and Hardware $(n=1,014)$

\begin{tabular}{|l|ll|}
\hline & $(1)$ & $(2)$ \\
\hline & $\ln ($ Personnel $)$ & $\ln ($ Hardware $)$ \\
\hline $\ln \mathrm{B}$ & $0.851^{* * *}$ & $0.925^{* * *}$ \\
& $(0.000)$ & $(0.000)$ \\
\hline Constant & $-0.760^{* * *}$ & $-1.592^{* * *}$ \\
& $(0.000)$ & $(0.000)$ \\
\hline R-squared & 0.823 & 0.833 \\
\hline
\end{tabular}

Notes: Model has an intercept and controls for year dummy variables. (1) $p$ values in parentheses; * significant at $10 \%$; ** significant at 5\%; *** significant at $1 \%$ (2) Industry dummies at single digit SIC included in the models but suppressed for presentation.

Table 4 provides further evidence in support of rejection of the homotheticity assumption. We find that firms have allocated a greater percentage of their IT budget to hardware, compared to that on IT labor (see Columns 1 and 2 of Table 4) because hardware prices are declining at a sharper rate than labor prices, consistent with arguments of Baumol. These differential allocations are statistically significant. The coefficients of year dummies in these models indicate that compared to 1999, firms have significantly increased their hardware budgets in all years after controlling for IT budget.

Hypothesis 3 predicted that IT production does not exhibit a constant and unitary elasticity of substitution in the network era and the ratio of personnel to hardware will change with time in response to changes in relative prices of personnel and hardware. Columns 1 and 2 of Table 5 provides a test to distinguish between Cobb-Douglas production function (implying fixed budget shares across years) and constant elasticity of substitution production function (implying changes in budget shares in response to changes in relative prices of hardware and personnel). Our models reject Cobb-Douglas production function. Our tests for $D_{h 0}=D_{p 0} ; D_{h t}=$ $D_{p t} ; C_{h t}=C_{p t} ; t=1,2, \ldots, T$ reject the null hypothesis at $p<0.01$ for $2002, p<0.05$ for 2001 and $p<0.10$ for 2000 and 2003 for the personnel-hardware models.

Overall, these results provide broad support for hypotheses 1,2 and 3. 
Table 5: SURE Models to Test for Hypothesis 3 $(\mathrm{n}=1,014)$

\begin{tabular}{|l|ll|}
\hline & $(1)$ & $(2)$ \\
\hline & $\ln ($ Personnel) & $\ln ($ Hardware $)$ \\
\hline $\ln \mathrm{B}$ & $0.882^{* * *}$ & $0.896^{* * *}$ \\
& $(0.000)$ & $(0.000)$ \\
\hline y2000 $\times \ln \mathrm{B}$ & -0.023 & 0.030 \\
& $(0.629)$ & $(0.533)$ \\
\hline y2001 $\times \ln \mathrm{B}$ & -0.037 & 0.044 \\
& $(0.438)$ & $(0.365)$ \\
\hline y2002 $\times \ln \mathrm{B}$ & -0.051 & 0.035 \\
& $(0.277)$ & $(0.462)$ \\
\hline y2003 $\times \ln \mathrm{B}$ & -0.031 & 0.023 \\
& $(0.516)$ & $(0.635)$ \\
\hline R-squared & 0.823 & 0.833 \\
\hline
\end{tabular}

Notes: (1) Models include an intercept and dummy variables for years. $p$ values in parentheses; * significant at $10 \%$; $* *$ significant at $5 \%$; $* * *$ significant at $1 \%(2)$ Industry dummies at single digit SIC included in the models but suppressed for presentation.

\section{Discussion}

Our goal in this paper was to revisit previous research findings with respect to production of IT services at the firm level using more recent data that covers the network era of computing after 1995, a period marked by significant investment in newer types of IT systems such as enterprise resource planning, customer relationship management and greater use of outsourcing, including offshoring of IT services.

Consistent with our expectations, we find that firms realize economies of scale in IT services as they grow in size. In other words, our results imply that firms need not increase their IT budget in the same proportion as revenue increases. These results also suggest that decreasing IT investments as a percentage of sales need not always be viewed as a significant cause for concern if they arise due to the existence of economies of scale in IS service production. Based on previous studies that showed an absence of economies of scale in IT services during the 1989-1994 period [2], one may be tempted to view declining IT investments (as a percentage of revenues) as a cause of concern. However, our study suggests that decreasing IT investments can be a manifestation of efficiencies realized by firms in managing IT without perhaps sacrificing their agility and ability to respond to customer and innovation needs by using IT. This finding also provides an explanation for the emergence of large IT vendors who are consolidating the IT services provided to their clients because doing so helps them realize economies of scale and thus enable them to pass on some of these gains due to efficiency to their clients. This finding also provides an explanation for evidence suggesting higher productivity, profitability and innovation output from IT investments in the recent time period [1,20].

We also find that the personnel-hardware ratio is not independent of IT budget, thus rejecting the previously maintained homotheticity assumption for newer kinds of IT systems. Rejection of the homotheticity assumption means that firms will change the ratio of personnel-to-hardware in response to changes in relative prices of these two components of costs. Therefore, we may not observe constant budget shares of hardware and personnel in the new environment.

Note that the findings showing economies of scale in IT investments and a decrease in personnelhardware ratio with a rise in IT investments are consistent because if the labor share of the IT investments decreased with scale then overall IT investments may "grow less than linearly with corporate revenue" as also recognized by Gurbaxani and colleagues [2, p. 1755].

Finally, we find that the personnel-hardware ratio was declining during 1999-2003 period in response to changes in factor prices of hardware and personnel, thus rejecting the validity of Cobb-Douglas function for IT services. Once again, this finding implies that the restrictive Cobb-Douglas function appropriate for earlier computing eras may no longer be appropriate for the network era for modelling IT budgets.

This study extends the work of Gurbaxani and colleagues by studying one of the most central artifacts of the IS discipline, that is, IT investments, and makes three important contributions.

First, our finding that there exist economies of scale in new information technologies provides a formal explanation for the current trend toward IT outsourcing because vendors with greater scale of operations can realize the economies of scale and pass on some of the benefits to their customers thus making it a win-win for all.

Second, we show that the homotheticity assumption does not hold for post-Internet IT investments made by firms after 1994. This finding has implications for future research in terms of modeling of provision of information services at the firm level.

Third, we show that firms allocate resources among different IT budget investments (e.g., personnel and hardware) such that the ratio of these investments does change longitudinally.

Our study also adds to the nascent literature on services science by demonstrating the adaptation of 
models developed for manufacturing to the services domain, in particular, IS services. Our results highlight a central feature of IS services: their dynamic nature. Accounting for computing eras when analyzing services related to IT is shown herein to be critical.

The findings of this study are important from a managerial perspective because IT investments are often considered "discretionary investments" like R\&D or advertising expenses, and they are not always a "strategic necessity" [21]. Not only do firms have a choice of how much they spend on IT but also in what proportion on different components of IT.

This study also has limitations that future research can try to overcome. First, it will be interesting to use more recent data, and results may even be stronger for more recent data due to emergence of cloud computing, automation of software development, and robotics. Second, future research should also try to incorporate other variables such as the role of Chief Information Officers (CIOs), use of foreign-born IT workers, increasing use of agile and DevOps approaches for software development, and global footprints of firms in the models for additional insights.

To conclude, this study revisits some of the fundamental questions pertaining to IT investments (i.e., the central IT artifact) such as the relationship between IS investments and firm size, the optimal personnel-hardware ratio, and how it changes in response to changes in factor prices. We address these questions in light of more recent and extensive data from the network era, when firms have made significant investments in newer types of IT systems (such as enterprise resource planning, customer relationship management) and greater use of outsourcing including offshoring of IT services. Overall, our findings suggest that the production of IS services is a dynamic phenomenon that must be studied against the backdrop of prevailing computing eras.

\section{References}

[1] S. Mithas, A. R. Tafti, I. R. Bardhan, and J. M. Goh, "Information Technology and Firm Profitability: Mechanisms and Empirical Evidence," MIS Quarterly, vol. 36, pp. 205224, 2012.

[2] V. Gurbaxani, K. Kraemer, and N. Vitalari, "An Economic Analysis of IS Budgets," Management Science, vol. 43, pp. 17451755, 1997.

[3] V. Gurbaxani, N. Melville, and K. Kraemer, "The Production of Information Services: A
Firm Level Analysis of Information Systems Budgets," Information Systems Research, vol. 11, pp. 159-176, 2000.

[4] S. Mithas, M. S. Krishnan, and C. Fornell, "Information Technology, Customer Satisfaction, and Profit: Theory and Evidence," Information Systems Research, vol. 27, pp. 166-181, 2016.

[5] N. Ramasubbu, S. Mithas, M. S. Krishnan, and C. F. Kemerer, "Work Dispersion, Process-Based Learning and Offshore Software Development Performance," MIS Quarterly, vol. 32, pp. 437-458, 2008.

[6] K. Han and S. Mithas, "Information technology outsourcing and non-IT operating costs: An empirical investigation," MIS Quarterly, vol. 37, pp. 315-331, 2013.

[7] S. Mithas and J. Whitaker, "Is the World Flat or Spiky? Information Intensity, Skills and Global Service Disaggregation," Information Systems Research, vol. 18, pp. 237-259, 2007.

[8] E. Clemons and M. Row, "McKesson Drug Company: A Case Study of Economost - A Strategic Information System," Journal of Management Information Systems, vol. 5, pp. 37-50, 1988.

[9] R. L. Nolan, "Information Technology Management from 1960-2000 (HBS Reference 9-301-147)," Harvard Business School, Boston, MA2001.

[10] S. Mithas and F. W. McFarlan, "What is Digital Intelligence?, https://www.computer.org/csdl/mags/it/2017 /04/mit2017040003.html," IEEE IT Professional, vol. 19, pp. 3-6, 2017.

[11] W. I. Frank, "The History of Myth No. 1," Datamation, vol. May, pp. 252-256, 1983.

[12] V. Gurbaxani and H. Mendelson, "Software and Hardware in Data Processing Budgets," IEEE Transactions on Software Engineering, vol. SE-13, pp. 1010-1017, 1987.

[13] V. Gurbaxani and H. Mendelson, "An empirical analysis of software and hardware spending," Decision Support Systems, vol. 8, pp. 1-16, 1992.

[14] S. Dewan and C. Min, "The Substitution of Information Technology for Other Factors of Production: A Firm Level Analysis," Management Science, vol. 43, pp. 16601675, 1997.

[15] Y. B. Chang and V. Gurbaxani, "IT Outsourcing and Firm Productivity: An 
Empirical Analysis," MIS Quarterly, vol. 36, pp. 1043-1063, 2012.

[16] R. J. Kauffman and A. Kumar, "A Combined Scale-and-scope Theory of IT Industry Cluster Growth," in In Proceedings of the 2006 IEEE International Society for Engineering Management Conference, Salvador, Bahia, Brazil, 2006.

[17] T. H. Davenport, "The coming commoditization of processes," Harvard Business Review, vol. 83, pp. 1-8, 2005.

[18] K. Kim, S. Mithas, and M. Kimbrough, "Information Technology Investments, and Firm Risk Across Industries: Evidence from the Bond Market " MIS Quarterly, vol. 41, 2017.

[19] T. Saldanha, S. Mithas, and M. S. Krishnan, "Leveraging Customer Involvement for Fueling Innovation: The Role of Relational and Analytical Information Processing Capabilities," MIS Quarterly, vol. 41, pp. 267-286, 2017.

[20] T. Ravichandran, S. Han, and S. Mithas, "Mitigating Diminishing Returns to R\&D: The Role of Information Technology in Innovation," Information Systems Research, vol. Forthcoming, 2017.

[21] S. Mithas, A. R. Tafti, and W. Mitchell, "How a Firm's Competitive Environment and Digital Strategic Posture Influence Digital Business Strategy," MIS Quarterly, vol. 37, pp. 511-536, 2013. 